\title{
Cladosporium oxysporum on Prunus nepalensis in India
}

\author{
P. Baiswar • S. Chandra • T. K. Bag • R. K. Patel • \\ S. V. Ngachan $\cdot$ Bidyut C. Deka
}

Received: 11 August 2010 / Accepted: 10 January 2011 /Published online: 12 March 2011

(C) Australasian Plant Pathology Society Inc. 2011

\begin{abstract}
Prunus nepalensis is grown as a fruit crop in Northeast India. Severe leaf blight was observed on almost $40 \%$ of seedlings grown in a polyhouse in Meghalaya, India. Light and scanning electron microscopy revealed the presence of Cladosporium oxysporum, which was confirmed by a pathogenicity test. To our knowledge this is the first report of leaf blight on $P$. nepalensis caused by $C$. oxysporum in India
\end{abstract}

\section{Keywords Cladosporium oxysporum $\cdot$ Prunus nepalensis}

Prunus nepalensis is an important fruit crop grown in Northeast India (Patel et al. 2008). Severe leaf blight symptoms were observed on 6-7 months old plants which were growing in a secondary nursery (polybags filled with 1:1:1 soil: sand: farm-yard manure) in a polyhouse at the Horticulture Research Farm of ICAR Research Complex for NEH Region, Umiam, Meghalaya, India. These seedlings were first grown in a primary nursery then moved to a secondary nursery after a month. In most cases, symptoms started at the leaf margins and extended towards the midrib. In the advanced stages of the disease whole leaves turned necrotic and heavy sporulation was evident on the lower surface of the leaves (Fig. 1). Sporulation was rarely seen on the upper leaf surfaces. The necrotic lesions were usually surrounded by a yellow halo (Fig. 2). Heavy defoliation of infected seedlings was

P. Baiswar $(\bowtie) \cdot S$. Chandra $\cdot$ T. K. Bag • R. K. Patel •

S. V. Ngachan $\cdot$ B. C. Deka

ICAR Research Complex for NEH Region,

Umiam 793103, Meghalaya, India

e-mail: pbaiswar@yahoo.com also observed. Symptoms were more severe on immature leaves. Seedlings and grafted plants (rootstock-P. nepalensis) were housed in the same polyhouse and grafted plants appeared to be more susceptible. Voucher specimens were deposited in the herbarium collection of MACS Agharkar Research Institute, Pune and ICAR Research Complex for NEH Region, Meghalaya, India (AMH No. 9332, ICARHNEH 138).

For pathogen isolation, leaf pieces taken at the edge of lesions with both infected and healthy portions were surface-sterilized using a $4 \% \mathrm{NaOCl}$ solution for 30 seconds. The sections were washed twice in sterile distilled water and placed onto PDA amended with streptomycin (100 ppm). Four day old isolation cultures were subcultured on Synthetic Nutrient Agar (SNA) at room temperature $\left(21 \pm 2^{\circ} \mathrm{C}\right)$ and diffused light conditions. Seven days old SNA cultures were used for morphological examination. Fungal structures produced on SNA were removed from the surface of the culture using a strip of Sellotape and mounted in $3 \% \mathrm{KOH}$ for light microscopy (Correll et al. 1987). A dissecting microscope was used to select suitable areas for scanning electron microscopy (SEM) observations. Leaf areas with abundant sporulation were cut into $5 \mathrm{~mm}$ size and placed on double sided Sellotape. Using a JFC-1100 fine coat ion sputter device (JEOL, Tokyo, Japan), samples were sputter coated with gold. Gold-coated samples were then placed on aluminum stubs in a JEOL JSM 6360 scanning electron microscope (JEOL, Tokyo, Japan).

For detailed microscopic observations, terms such as primary and secondary ramoconidia, intercalary and terminal conidia were used as described in Schubert et al. (2007). Conidiophores were macro- as well as micronematous, also branched in a few cases. Macronematous conidiophores measured (61-) 67.5-229.5 (-284.5) $\times 3-$ 
Fig. 1 Symptoms on Prunus nepalensis leaves showing the progressive stages of leaf blight from initial necrosis at the margins (a) to widespread (b) and then complete necrosis $(\mathbf{c})$

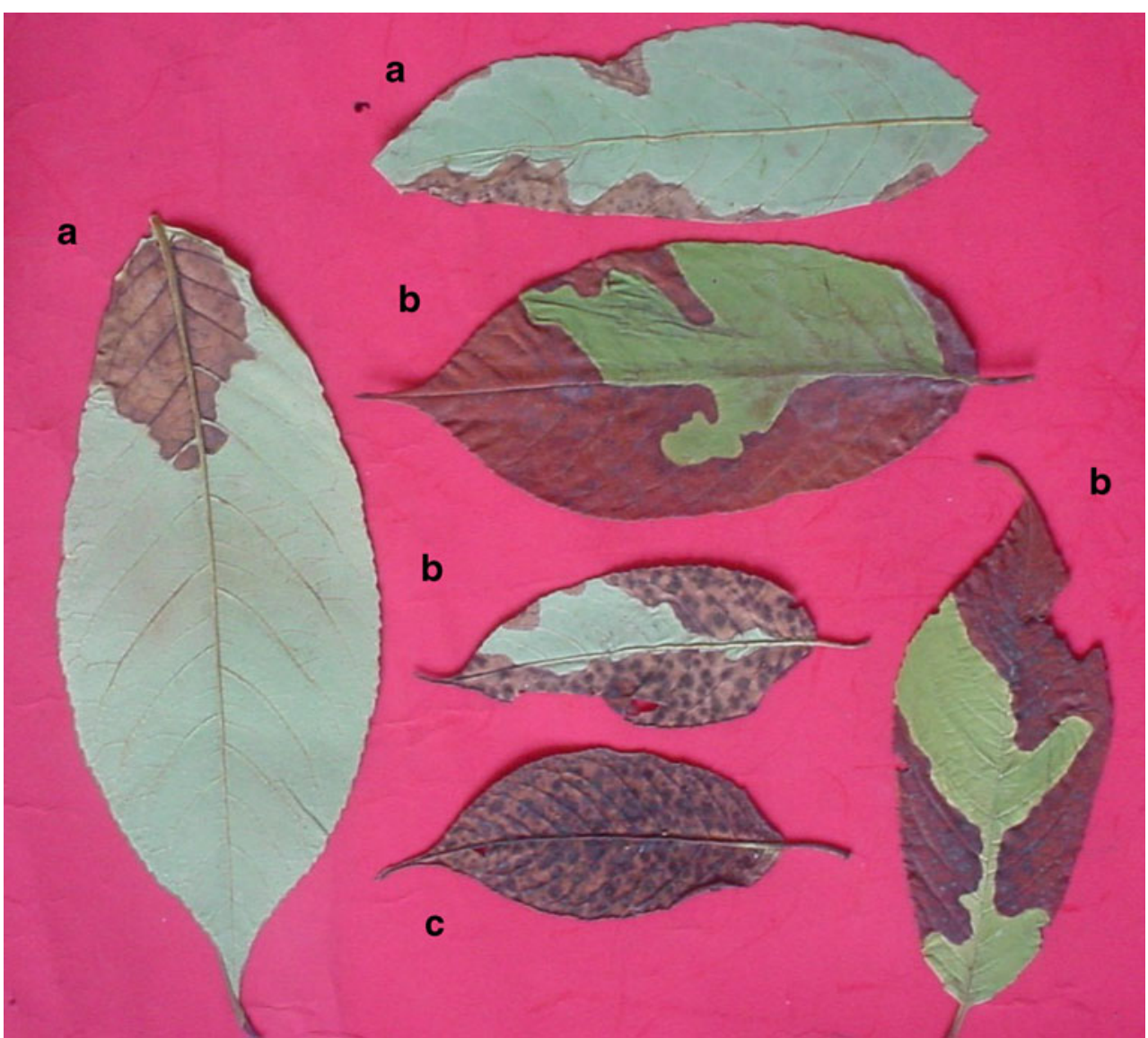

$5.5 \mu \mathrm{m}$, micronematous conidiophores $15.5-42.4 \times 2.5-$ $3.5 \mu \mathrm{m}$, terminal conidia $2-4(-4.5) \times 2-3 \mu \mathrm{m}$, intercalary conidia 3.5-6 $(-7) \times 2-3.5 \mu \mathrm{m}$. Ramoconidia were rare and measured (10.5) $11.5-33 \times 2.5-3.5 \mu \mathrm{m}$. Secondary ramoconidia were $0-1$ septate and measured (5.5-) 6-26 $(-39.5) \times(2-) 2.5-3.5 \mu \mathrm{m}$. Conidia as well as conidiophores were light brown. For confirmation of scar type on conidiophore, conidial hila and surface patterns on conidia SEM observations were also made. SEM observations confirmed the presence of coronate scar and conidial hila (central dome surrounded by a raised rim) and smooth conidial surface (Fig. 3a). Presence of a central dome surrounded by a raised rim observed in SEM placed this fungus in the genus Cladosporium (Crous et al. 2007). The smooth surface of the conidium which is more evident on the intercalary conidium and the dimensions gave the indication of $C$. cladosporioides (Schubert et al. 2007). C. cladosporioides was considered as a species complex and was in need of revision (Zalar et al. 2007). But this species complex has been explored by Bensch et al. (2010) very recently. Combination of characters like presence of smooth, catenate conidia and macronematous conidiophores with swellings indicate that this pathogen belongs to C. oxysporum (Bensch et al. 2010) (Figs. 3b, and 4).
Cladosporium is differentiated from other anamorphs of Mycosphaerella by its unique type of scars on conidiophores and conidial hila (coronate or Cladosporium type i.e. central dome surrounded by a raised rim) (David 1997 cited in

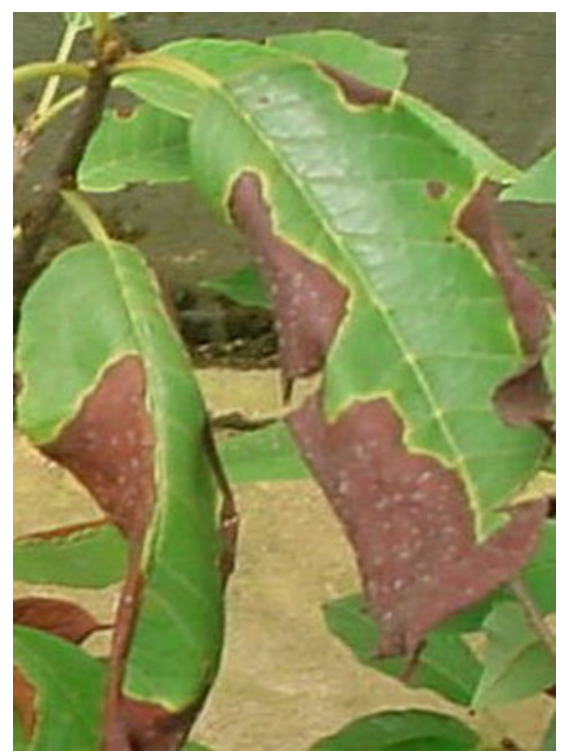

Fig. 2 Necrotic lesions surrounded by a yellow halo on infected Prunus nepalensis leaves 
Fig. 3 Scanning electron micrograph of conidiophore (a) and conidia (b) of Cladosporium oxysporum $\mathrm{Bar}=2 \mu \mathrm{m}$
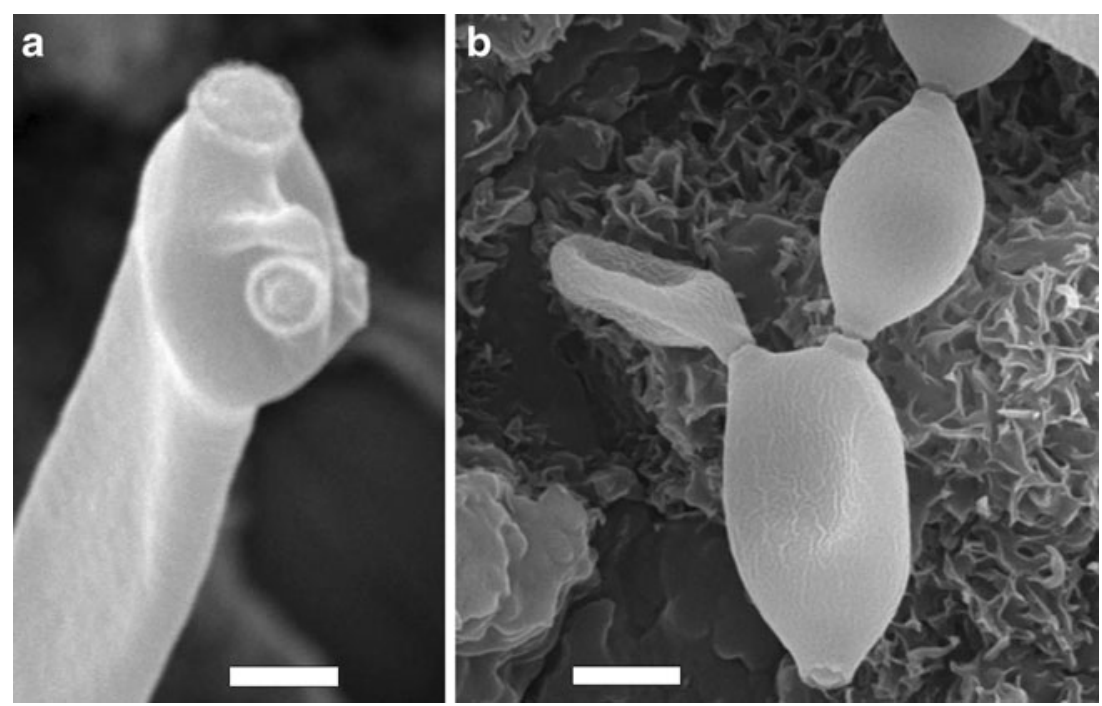

Schubert 2005). Separation of this genus based on these criteria has also been supported by molecular evidence (Crous et al. 2007; Braun et al. 2003). The genus Davidiella was proposed as a teleomorph for Cladosporium anamorphs which were earlier placed in Mycosphaerella sensu lato (Braun et al. 2003).

In order to confirm Koch's postulates, pathogenicity was tested by spraying a conidial suspension prepared from cultures on PDA $\left(10^{6}\right.$ conidia $\left./ \mathrm{ml}\right)$ in sterile water on healthy seedlings of $P$. nepalensis (6-7 months old). Control plants were sprayed with sterile water. Plants were kept in a polyhouse (average minimum temp. $23^{\circ} \mathrm{C}$, max. $38^{\circ} \mathrm{C}$ and relative humidity $65 \%$ ). Symptoms appeared 2 weeks post-inoculation on inoculated plants and control plants remained asymptomatic. Reisolation was done from plants showing symptoms and morphological characters were compared, confirming the causal agent as $C$. oxysporum. C. oxysporum is also considered as a saprobic fungus but pathogenicity tests in our case proved it to be the cause of the leaf blight. C. oxysporum has been reported as a pathogen on several plants (Farr and Rossman 2010).

To our knowledge this is the first report of $C$. oxysporum on P. nepalensis.
Fig. 4 Swellings on macronematous conidiophores of Cladosporium oxysporum $\mathrm{Bar}=10 \mu \mathrm{m}$

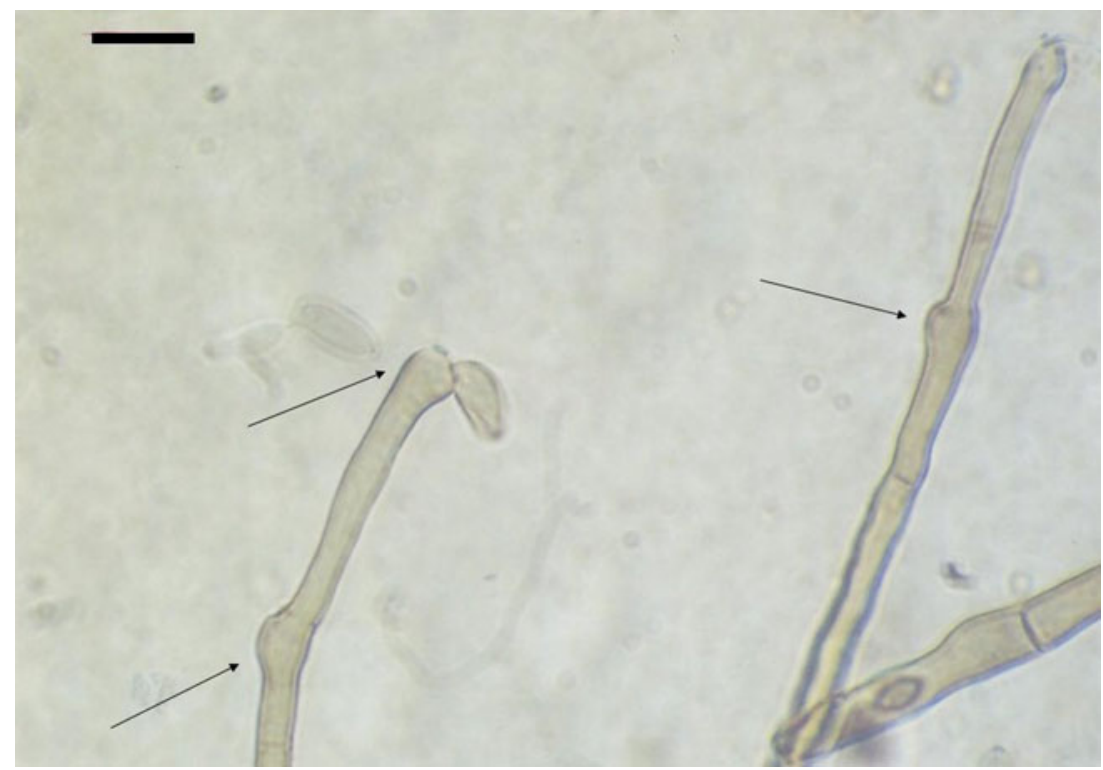


Acknowledgements Authors would like to thank Head SAIF, Dr Sudeep Dey (Scientific Officer), N. K. Rynjah, and Dr R. Charkraborty for scanning electron microscopy at Northeastern Hill University, Shillong, Meghalaya, India.

\section{References}

Bensch K, Groenewald JZ, Dijksterhuis J, Starink-Willemse M, Andersen B, Summerell BA, Shin HD, Dugan FM, Schroers HJ, Braun U, Crous PW (2010) Species and ecological diversity within the Cladosporium cladosporioides complex (Davidiellaceae, Capnodiales). Stud Mycol 67:1-94

Braun U, Crous PW, Dugan F, Groenewald JZ, de Hoog GS (2003) Phylogeny and taxonomy of Cladosporium-like hyphomycetes, including Davidiella gen. nov., the teleomorph of Cladosporium s. str. Mycol Prog 2:3-18

Correll JC, Gordon TR, Elliott VJ (1987) Host range, specificity and biometrical measurements of Leveillula taurica in California. Plant Dis 71:248-251
Crous PW, Braun U, Schubert K, Groenewald JZ (2007) Delimiting Cladosporium from morphologically similar genera. Stud Mycol 58:33-56

David JC (1997) A contribution to the systematics of Cladosporium. Revision of the fungi previously referred to Heterosporium. Mycol Pap 172:1-157

Farr DF, Rossman AY (2010) Fungal Databases, Systematic Botany \& Mycology Laboratory, USDA: ARS. Available at http://nt.ars-grin. gov/fungaldatabases

Patel RK, Singh A, Deka BC, Ngachan SV (2008) Handbook of fruit production. ICAR Research Complex for NEH Region, Meghalaya

Schubert K (2005) Taxonomic revision of the genus Cladosporium s. lat. 3. A revision of Cladosporium species described by J.J. Davis and H.C. Greene (WIS). Mycotaxon 92:55-76

Schubert K, Groenewald JZ, Braun U, Dijksterhuis SM, Hill CF, Zalar P, de Hoog GS, Crous PW (2007) Biodiversity in the Cladosporium herbarum complex (Davidiellaceae, Capnodiales), with standardisation of methods for Cladosporium taxonomy and diagnostics. Stud Mycol 58:105-156

Zalar P, de Hoog GS, Schroers HJ, Crous PW, Groenewald JZ, GundeCimerman N (2007) Phylogeny and ecology of the ubiquitous saprobe Cladosporium sphaerospermum, with descriptions of seven new species from hypersaline environments. Stud Mycol 58:157-183 